\title{
A NEW ROLE FOR MANAGEMENT OF THE SOCIAL SCIENCES IN AN AGE OF COMPLEXITY
}

A particular scientific world view has become dominant, influential and successful in modern sciences today. Science and technology have transformed the way we view ourselves, our societies and our place in the cosmos. However, just as science and technology seem to be at the peak of their power, unexpected problems are disrupting the sciences from within. This reflects a deeper and more serious problem regarding scientific inquiry. Science is being held back by old assumptions that have become dogmas, the biggest of which is that science already knows all the answers, and only the details need to be worked out. A transformational paradigm shift is required from a mechanistic world view to an organic world view to better address the challenges of the new millenium.

Keywords: sciences, paradigm shift

Every original idea is imaginative, because only imagination can trigger creativity. This is why imagination is just as essential in science and technology as in the arts and humanities. The difference between these two pairs of fields is that in science and technology imagination is disciplined rather than free.

$$
\text { Mario Bunge (2012, p. 1.) }
$$

In his book, Science Set Free: Ten Paths to New Discovery, Rupert Sheldrake (2012) discusses the 'scientific worldview' that has become dominant, influential and successful in modern sciences today. He agrees that our lives have been profoundly influenced by the advancement of scientific endeavor in medical research and technology. This has transformed the way we view ourselves, our societies and our place in the cosmos. But, he says, "in the second decade of the twenty-first century, when science and technology seem to be at the peak of their power, when their influence has spread all over the world and when their triumph seems indisputable, unexpected problems are disrupting the sciences from within" (Sheldrake, 2012, p. 6.). Sheldrake says that most scientists accept that these problems will eventually be solved by continuing the same kind of research and practise from which the problems and tensions emerged, and this he believes reflects a deeper and more serious problem regarding scientific inquiry (Sheldrake, 2012, p. 6.). Sheldrake argues that science is being held back by old assumptions that have become dogmas, the biggest of which is that science already knows all the answers, and only the details need to be worked out. The contemporary scientific creed is based on the 10 core beliefs or dogmas below:

1) Everything is essentially mechanical.

2) All matter is unconscious.

3) The total amount of energy and matter is always the same.

4) The laws of nature are fixed.

5) Nature is purposeless.

6) All biological inheritence is material.

7) Minds are inside heads and are nothing but the activity of brains.

8) Memory is stored in material traces of the brain.

9) Unexplained phenomena such as telepathy are illusory.

10) Mechanistic medicine is the only one that really works.

Sheldrake's arguments are presented with many clear examples that show how these beliefs compose the philosophy or ideology of materialism, where everything is essentially material or physical, even the 
human mind. His purpose is to „set science free,” from its own dogmas to increase its relevance and credibility to tackle really existing problems.

In Samuel Arbesman's (2012), The Half-Life of Facts: Why Everything We Know has an Expiration Date, an anecdote is related that many medical schools tell their students that half of what they have been taught will be wrong within five years - the teachers just don't know which half. What we know about the world is constantly changing, yet our approach to knowledge and the management of the communication of that knowledge has remained the same. The extreme technical and specialized nature of contemporary scientific discourse alienates all but the initiated, creating an increasing gulf between the sciences and the societies in which they work. This is quite suprising considering the explosion and proliferation of the information society, and the possibilities this provides for better communication management and dialogue.

Arbesman comes from the field of 'scientometrics', which is the study of measuring and analysing science, technology and innovation, or the science of science. He explains that knowledge in most fields systematically and predictably evolves. In some fields, change occurs over a few years, in others over centuries. But most of what we know are called 'mesofacts' that often change over a single human lifetime. This is important because if we are more aware of how our knowledge changes over time, we are better equipped to deal with contemporary challenges, like improvement in the allocation of resources by companies or governments, for example.

Science is absorbed with its role to explain the nature of everything, and then tries to convert others to believe in the particular methods, explanations and models. For example, since the 1960s, physicists and mathematicians have developed a framework called 'string theory' to try and reconcile general relativity with quantum mechanics. Over the years, "it has evolved into the default mainstream theory, even as it has failed to deliver on much of its early promise" (Powell, 2015). The same article discusses the implications for Einstein's theory of relativity, and the basic assumption (going back to Aristotle) that space is continuous and infinitely divisible, so that any distance could be divided into even smaller distances. This is being questioned by Craig Hogan, a theoretical astrophysicist at the University of Chicago and the director of the Center for Particle Astrophysics at Fermilab who argues that there might be an unbreakable smallest unit of distance: a quantum of space.

What emerges from the dust-up could be nothing less than a third revolution in modern phys- ics, with staggering implications. It could tell us where the laws of nature came from, and whether the cosmos is built on uncertainty or whether it is fundamentally deterministic, with every event linked definitively to a cause (Powell, 2015).

There have been many great feuds in science that have been popularized in accounts like Hellman's Great Feuds in Science; Great Feuds in Technology; Great Feuds in Mathematics (1998, 2004, 2006 respectively), of Levy's (2010) Scientific Feuds: from Galileo to the Human Genome Project. In many of these cases the asuumption that science has successfully delivered accurate knowledge based on authoritative sources does not bear close scrutiny.

Scientists with radically new ideas have difficulty getting an audience among their more orthodox brethren. Sometimes they are ignored or rejected because of personal animosities or simple inertia. In other cases, the rejection seems to violate the canons of open-minded scientific inquiry. Through the whole spectrum of the sciences, one can document an astonishing disregard for facts which contradict fashionable theories, stereotyping of acceptable approaches to problems and theories, and the waving of academic credentials and ritual invocation of the specialist's mystique to discourage criticism from 'outsiders' (Judge, 2012).

Science is engrossed with the importance of "validation', which is most often carried out in the framework of statistical analysis, that often excludes other factors that may appear to be at least as significant if not more than others. This reflects 'downstream thinking', that is, a blind focus on imminent causes rather than on the root causes of phenonena, as is the case with many social issues and challenges, including the present migration crisis and terrorism.

Besides the obsession with validation, some other systemic knowledge processes that are neglected by science are outlined here by Judge (2012) as an expansion of Sheldrake: selective appreciation of the creative imagination; unexamined preoccupation with professional reputation and recognition (self-referencing, references in peer-reviewed journals); deprecation of alternatives and anomalies that challenge conventional models; methodogical dependence on questionable engagement with society; uncritical belief of science in the appropriateness of its own process; institutionalized incoherence and disagreement; lack of recognition of the constraints and opportunities of an information society; self-referential inadequacy of 'metascience'. 
In Sheldrake's (2012) final chapter, „The Illusions of Objectivity," he questions the 'objectivity' of science, by asking the question „whose objectivity?” Science praises innovation and creativity only within the currently accepted paradigm that is approved by accepted scientific authorities. For example, the imaginative reframing of paradigms is most often disparaged by the old order, until the new paradigm comes into full being which, most often, occurs after the proponents of the old order have died.

The current practise of science inhibits creative and imaginative thinking in most fields, thereby reinforcing the general tendency to capitulate to present authorities. While the tendency of science is to deprecate or condemn alternative worldviews, there is little capacity of science to reflect on these processes and to discover more holistic ways of relating to perspectives that challenge the current order. This incapacity or reluctance is reinforced also in other sectors of society, in governance and management structures (see below), and the practise of democracy. In other words, there is an uncritical belief of science in the appropriateness of its own process (Judge, 2012). This is complicated by the fact that government and industry supported scientific research is many times complicit with the prevailing power structures, on whom it depends for research funding.

Loren Eiseley (1964), wrote that all human undertakings are driven by the imagination, be they artistic, scientific, or humanistic. The danger lies in the strict enforcement of the separation of academic disciplines, and the cult of 'professionalism' based on the self-acknowledgement of approved authorities, that is depleting the creative and imaginative power of the sciences. He passionately laments the loss of the capacity to wonder in a divided, money-driven world of big science. He rearticulates, in fact, Einstein's thought:

"The most beautiful thing we can experience is the mysterious. It is the source of all true art and science. He to whom the emotion is a stranger, who can not longer opause to wonder and stand wrapped in awe, is as good as dead - his eyes are closed."

\section{Paradigm Shift}

Our whole world society appears to be following a distinct pattern that occurs very rarely in history, one that has led in the past to total reinventions of the world within very short periods of time. In short, we are in the midst of a classic paradigm shift and are fast approaching the tipping point of the whole process.

Michael Shacker (2013, p.31.)
The present crises are connected by a mechanistic world view that has dominated for the past 300 years and that has endangered the environment and quality of life, societies and individuals. In a mechanistic world view, we all become parts of the machine and mere objects, reified, commodified. The fatal flaw of a mechanistic world view is eloquently elaborated by Michael Shacker (2013) in his work, Global Awakening, New Science and the $21^{\text {st }}$ Century Enlightenment. Referring to William Barret's (1979), Illusion of Technique, he explains that the smooth operation of the machine becomes everything in the mind of the technician; and since there is no meaning that can be derived from a machine, life becomes meaningless.

Our whole mechanistic society now reflects this meaningless and purposeless world view.... The illusion of technique helps us understand this fatal flaw of mechanistic dogma and how it fails to confront reality. In short, the lure of the machine outweighs the mounds of scientific data showing the fragile interconnections of Earth and its biosphere. Social, environmental and health concerns are swept under the rug and ignored. The mechanistic paradigm is thus dysfunctional at its core - so we find ourselves in the mechanstic dilemma (Shacker, 2013, p. 29-30.).

$\mathrm{He}$ continues by addressing the necessity of "more-than-ordinary" thinking and action to transcend the mechanistic dilemma to extract the planet and humanity from its current precarious situation.

The crisis is further exacerbated by the collusion between big business and increasingly self-defensive, nationalistic governments who, in order to maintain their power positions and monopolistic control of market forces, will not willingly relinquish their power positions. This is clearly seen in the increasing incidents of state violence by state sanctioned police forces against populations that have arisen to protest against economic and social inequalities resulting from the financial crisis and increasing economic consolidation of the $1 \%$, as well as aspirations for a more democratic politics of participation.

What is common in the many ways the states and their authorities, and economic players react is their strong insistence on historic divided-ness and cultural differences as well as the complete lack or rejection of the holistic approach in dealing with grave social, political, economic, and ecological problems. Threatened in their existence and legitimacy, old institutions, interest groups and other powerful global, regional and national stakeholders are keen to entrench themselves and fight 
one another to secure their interests and survival. The new wave of disintegration and self-isolation is a result of the failure of global and regional 'caretaker'or 'guardian' institutions such as the UN, the WTO, the World Bank, the IMF or the European Union. Instead of contributing globally and regionally to more democracy, equality, peace and human security, these institutions themselves contribute to the survival of the old paradigm of inequality and division, human vulnerability and insecurity. A new paradigmatic approach should ensure the acceptance and understanding of the inevitability of a holistic view of humankind, together with its self-created institutions, markets, nationstates and means of violence. The vision and practice of a wisdom based society that turns knowledge into organic and holistic practices has to gradually replace the old paradigm of a knowledge-based society that was established on the premise and special historical understanding of fragmentation and division. Awareness of increasing interdependence and interconnection in various spheres of our common existence is a slow process that needs to speed up to reflect a new planetary and species consciousness.

\section{The Structure of Scientific Revolutions: Medieval, Mechanistic and Organic World Views}

A new scientific truth does not triumph by convincing its opponents and making them see the light, but rather because its opponents eventually die.... Max Planck (1949, p. 33-34.)

Every world view needs to answer the fundamental questions of who we are, how we got where we are, and where we are going that is delivered in a new story or narrative frame. The current crisis of world view requires a paradigm shift which will move humanity into a new world system and mind-set. Paradigm shifts or 'flips' have occured before. Thomas Kuhn (1962) formulated the structure of scientific revolution as follows:

- Emergence of an anomoly that contradicts the old world view. Nature violates the expectations of normal sciences and answers have to be found outside the paradigm.

- The emergence of a new paradigm or way of thought. A revolutionary period upsets the stability of the normal science period.

- Crisis ensues and there is reconsideration of the old paradigm by new thinker(s) to explain anomolies and a new narrative emerges.

- Bitter struggle develops; there is resistence to the new from old scientists; paradigm wars are fought by the new world view with facts and by the old world view with ideology.

- The new paradigm wins the struggle, and a new normal science period begins with the new underlying analogy/model, new scientific methods, and a changed set of rules.

Since humanity has experienced this before, Michael Schacker has presented the evolution of historical paradigms in the following way. (Table 1 and 2)

I have adjusted Kuhn's scientific revolution and incorporated Shacker's paradigm shift into our contemporary period in the following:

I. The Emergence of Anomolies, 1970s to the present

- increase in the number of economic crises and market volatility,

- increase in the number of manmade disasters,

- population increases, as well as industrial material exploitation, put increased strain on the natural environment,

Comparison of Medieval and Mechanistic World Views (Shacker, 2013, p. 36.)

\begin{tabular}{|l|l|}
\hline Medieval World View & Mechanistic World View \\
\hline God is responsible for all events on earth. & $\begin{array}{l}\text { God or nature merely sets universe in motion, natural } \\
\text { law determines the rest; clockwork universe of Newton. }\end{array}$ \\
\hline God's creation only 6000 years old. & $\begin{array}{l}\text { Universe very old, Earth millions to billions years old, } \\
\text { formed by natural forces. }\end{array}$ \\
\hline Two sets of laws: one for Earth, one for heaven. & One set of natural laws governs Earth and the universe. \\
\hline Geocentric universe: Earth does not move. & Helocentric solar system: Earth orbits the sun. \\
\hline King and nobility have divine right to rule. & $\begin{array}{l}\text { The right to govern derives from the people; kings are } \\
\text { tyrants. }\end{array}$ \\
\hline $\begin{array}{l}\text { Medieval laws and value system designed to protect the } \\
\text { lands and power of kings, the aristocracy and the chur- } \\
\text { ch. }\end{array}$ & $\begin{array}{l}\text { Laws and values designed to provide liberty and equa- } \\
\text { lity to all men, to protect the pursuit of happiness, and to } \\
\text { derive power from the people in a democracy. }\end{array}$ \\
\hline
\end{tabular}




\section{Comparison of Mechanistic and Organic World Views (Shacker, 2013, p. 41.)}

\begin{tabular}{|c|c|}
\hline Mechanistic World View & Organic World View \\
\hline $\begin{array}{l}\text { Limited mechanistic models underlie traditional sci- } \\
\text { ence and medicine and cannot explain living systems } \\
\text { adequately; ecological, health and economic break- } \\
\text { downs. }\end{array}$ & $\begin{array}{l}\text { Encompassing organic/biological models underlie } \\
\text { new-paradigm sciences from physics to agriculture, me- } \\
\text { dicine, technology, economics, and psychology. }\end{array}$ \\
\hline $\begin{array}{l}\text { Clockwork universe, no purpose assigned to humanity } \\
\text { or universe; we live in a vast static cosmos. }\end{array}$ & $\begin{array}{l}\text { se and evolution means we } \\
\text { ext level. }\end{array}$ \\
\hline $\begin{array}{l}\text { Anthropocentric universe; planet Earth treated as a } \\
\text { non-living thing to be exploited. }\end{array}$ & $\begin{array}{l}\text { Complexity-centered universe: planet Earth shown to } \\
\text { be a living system. }\end{array}$ \\
\hline ysics limited to macroworld, non-living & ies sub-atomic realm; law of organics \\
\hline Time and space quantified. & ified and given me- \\
\hline Studi & \\
\hline $\begin{array}{l}\text { Old paradigm culture based on oil, ultranationalism and } \\
\text { militarism; huge military budget, small foreign aid; top } \\
1 \% \text { owns } 45 \% \text { of wealth. }\end{array}$ & $\begin{array}{l}\text { Counterculture based on transition from oil, world pea- } \\
\text { ce and sustainable development; increase foreign aid to } \\
\$ 50 \text { billion to stop terrorism; new economics to elimi- } \\
\text { nate poverty. }\end{array}$ \\
\hline $\begin{array}{l}\text { Laws and values designed to protect the rights of men, } \\
\text { especially corporations and men with property. }\end{array}$ & $\begin{array}{l}\text { Laws and values designed to protect the rights of all, } \\
\text { from women to blacks, gays and all minorities, especi- } \\
\text { ally the poor and middle class. }\end{array}$ \\
\hline Belief that war has always been a part of human & $\begin{array}{l}\text { War has been invented and can be transcended in a fu- } \\
\text { ture world of peace. }\end{array}$ \\
\hline
\end{tabular}

- increased concentration of corporate global power (see the definitive study by Vitali - Glattfelder Battiston, 2011),

- increased economic inequality within and between nations and regions.

II. The Backlash Phase, 1980-1995

- conservative backlash, fundamentalist revivals (but they begin to slowly break down because of internal divisions and corruption),

- rise of the New Right (Reagan and Thatcher - government is evil, free market is infallible),

- scandals pile up: bailouts (already in 1984, a Savings and Loan bailout for more than $\$ 400$ billion), arms deals, resisting end to apartheid, Lebanon invasion, rise of Saddam Hussein, AIDS and women's rights ignored,

- increasing environmental catastrophes: Chernobyl, Bhopal, Exxon Valdez, Fukushima - the mechanistic dilemma deepens. Recognition that the mechanistic world view can never solve the problems of its own making.

III. The Intensive Phase (1991-2011)

- regressive presidencies,
- corporate world domination (oil wars, GMOs),

- activist Millenial or Phoenix Generation (Dennis, 2015),

- integrative medicine,

- global education - the Future University ('Multiversity'),

- regenerative regional planning (e.g., Kőszeg KRAFT project, see, Miszlivetz et al., 2014).

IV. The Transformational Phase/ Existential Challenges (2012-2050)

- climate change, and exponential population growth repercussions and the development of alternative energy sources,

- the future of employment: technological unemployment; social versus market values,

- new economic models: prosperity without growth, green and blue economies, sharing economy and participatory economics, community capitalism, resource-based economy and the collaborative commons,

- reinventing governance, democracy and political participation,

- regenerative revolution: new economics, technological/social innovation will replace the macroe- 
conomics machine models of today. It will be based on organic development and the interdependence of life processes. (see, e.g., www.GlobalRegen.net, www.kraftprojekt.hu).

\section{A Tale of Two Cultures}

A great poet is always timely. A great philosopher is an urgent need. There's no rush for Isaac Newton. We were quite happy with Aristotle's cosmos. Personally, I preferred it. Fifty-five crystal spheres geared to God's crankshaft is my idea of a satisfying universe. I can't think of anything more trivial than the speed of light. Quarks, quasars - big bangs, black holes - who gives a shit? How did you people con us out of all that status? All that money? And why are you so pleased with yourselves? ... If knowledge isn't self-knowledge it isn't doing much, mate. Is the universe expanding? Is it contracting? ... Leave me out. I can expand my universe without you.

From Tom Stoppard's play Arcadia (1993), quoted in Jacobs (2014)

The division of scientific disciplines is recognized as both old and new. Some authors (Dirks, 1996) trace the origins back to the ancient Greeks, and already in the 16th century scholars and philosophers complained about the fragmentation of knowledge (e.g., in the works of Sir Francis Bacon we clearly encounter the disruption of relations between science and social philosophy). At the base of this divergence was the rapid growth and expansion of the sciences.

For many years, Immanuel Wallerstein wrote about the two cultures of scholarship. But before we expand on Wallerstein's analysis, a brief discussion on the background of the debate is necessary. Wallerstein based his reasoning on both the lecture and publications of C.P. Snow (1959), on the topic of the two cultures, that is science and philosophy (The Two Cultures and the Scientific Revolution). This debate was actually introduced even earlier in the 1880s by Mathew Arnold in another Rede Lecture in 1882, entitled "Literature and Science," a clear precursor to Snow's later lecture, and in letters responding to Thomas Henry Huxley's advocacy of scientific endeavor over the study of humanities. Arnold's response takes a practical look at the education of young people, arguing "that while the study of the sciences could fill the mind with facts, the humanities could move the human spirit" (Jacobs, 2014). Arnold emphasized the need for culture to be protected in order to guide human conduct in the face of moral challenges presented by modern science. This could not be more relevant today considering the challenges facing societies relating to, for example, genetic engineering, increasing weapons of mass destruction, and the underlying assumption that every problem we face has a technological solution.

What Snow later developed in his Rede Lecture in 1959 emphasized that because of the expansion of intellectual specialization in the 19th century, the sciences and humanities had become mutally incomprehensible to one another. The gulf between these two cultures of thought was deliberate and a clear product of 19th century thinking. Science was assigned the task of looking for 'truth'; while philosophy, and what became know more generally as the humanities (history, and later economics, sociology, and political science), was positioned to search for the 'good'. The progress of the last 200 years has tried to reunite the search for 'truth' and the search for the 'good' under the label of social science as established in the 19th century. In the 19th century, the disciplinary boundaries took shape at universities. After WW II, massive expansion and development of univeristies consisted of the formation of more and more disciplines and departments. One problem of the rapid growth of science was that there was too much information spread across the disciplines for any one person to handle. This has only been exacerbated in the 20th and 21st centuries with technological developments and the $24 / 7$ provision of information to many researchers and academics.

Wallerstein observes, that rather than reunifying these two cultures, social science has itself been torn apart by the dissonance between the two distinct approaches to inquiry, or cultures of knowledge. But Wallerstein (1999) recognizes two remarkable intellectual developments of the last decades that perhaps provide evidence of a process of overcoming the split of the two cultures that points towards a more holistic approach to scientific analysis. The first is called 'complexity studies' in the natural sciences, and the other is called 'cultural studies' in the humanities. Complexity studies rejects the Newtonian science that assumed that there were simple underlying formulae that explained everything. Complexity studies, Wallerstein argues, reveals rather that formulae can at best reflect only partial reality, that may explicate the past, but never the future. This is a transformation that Ilya Prigogine (1996) called moving from a 'geometrical universe' to a 'narrative universe'. The universe is filled with structures that constantly evolve, and then reach points of inequilibrium that cannot be sustained, when bifurcation takes place and new paths are found and new structures and systems established. Although we do not know what, for example, a new world system or structure will look like, as individuals and collectives we can have more impact at these times, because we are not under the constraints 
of the old or emerging new world system. Therefore, the age we live in is more open to human intervention and creativity (Wallerstein, 2000, p. 251-252.).

Cultural studies do not just study culture as such anymore, but rather how, when, why and in what forms culture is produced, and how cultural products are received by others, and for what reasons. Therefore, cultural studies has moved away from the traditional humanities into the realm of the social sciences and the explanation of reality as a constructed reality.

With the move of natural science towards social sciences via complexity studies, and the move of humanities towards the social sciences via cultural studies, we are in the process of overcoming the two cultures of knowledge by recognizing that reality is constructed. This gradual process of overcoming the artificial distinction between hard and separate disciplines, and moving towards the unification of scientific and human endeavor, provides the basis not only for holistic scientific enquiry, but for the basis of new, regenerative educational models, and 'multi-versities' as oppose to 'uni-versities'. Pinker (2014) declares that instead of science being the enemy of humanities, that they both share a common enemy which is an educational system that avoids addressing the complex and varied global challenges of our age. Real and exacting critical training in any field is essential in order to prepare young people today for the unexpected uncertainities and surprises they will face.

In academic scholarship (research as well as education), particularly in the social sciences, there is an increasing tendency to try to bridge the fragmentary nature of knowledge to create truly transdisciplinary methodologies. New methodology is needed that is not tied to compartmentalized disciplinary categories that reflect and reproduce a mechanistic world view. Knowledge produced through the cross-fertization of tools, information and methodologies requires a new type of university that can aid in the production of a complex understanding of contemporary global challenges. A 'multiversity' needs to be different in fundamental ways from today's obsolete, out-of-touch, and petrified institutions. New institutions should be 'learning' and not just teaching institutions where the co-creation of knowledge is translated into programs that promote self-reflection and self-correction, in systems, policies and societies. This way new knowledge hubs can steadily reconfigure their own capacities to include new partners and methods to assess and address changing realities. The social and natural sciences, as well as technical innovations, should also be socially responsible. In the first place, the question needs to be asked: does the research serve the interests of societies and if so, in what ways will it be useful identifying and providing relevant alternatives for solutions to problems.

\section{Integrative Cognitive Tools: Wholeness and the Implicate Order Revisited}

...science itself is demanding a new, non-fragmentary world view, in the sense that the present approach of analysis of the world into independently existent parts does not work very well in modern physics. It is shown that both in relativity theory and quantum theory, notions implying the undivided wholeness of the universe would provide a much more orderly way of considering the general nature of reality.

David Bohm (1980, p. xiii.)

... Science is in transition to a new form of rationality based on complexity, one that moves beyond the rationality of determinism and therefore of a future that has already been decided. And the fact that the future is not given is a source of basic hope.

Immanuel Wallerstein (1999, p. 166-167.)

The main challenges are to overcome dogma, complacency and the neglect to reflect on scientific processes, 'objectivity' and underlying structures; at the same time enabling the synergistic exploration of trans-disciplinary research in order to imagine new worlds and new futures through a collective process of co-creation. This can take the form of the 'wisdom of crowds' approach by Surokiecki (2004), Csermely (2015), among others. A brief summary of my own research is based on the inadequacy of current analytical models to assess and analyze the new methods and pervasiveness of social organization at the global level. Through the application of complexity theory and the study of the 'emergence' of new cultural forms, new narratives, and new networks under the surface of societies, a better framework is approached to account for the diversity and spread of new networks of social connectivity and activism. When initiatives emerge to the surface they can presage fundamental social and structural changes. I have found that the emergence of new 'order' in complex systems is prompted by small, singular events that result in small disorders that intensify and cause instability where the novelty emerges. If the new issues, methods, identities, structures and forms of protest are widely imitated, then what began as a singular innovation can spread within the protest system and transform it. This critical phase reflects the idea that, dependent on initial conditions, small causes can have large effects. The qualities of self-organization, networking, and synergy as emergent qualities can then be employed to construct a dynamic concept of contemporary protests. 
Another application to our interconnected and interdependent planet emerges from 'entanglement theory' which describes how particles of energy or matter can become correlated to predictably interact with each other regardless of how far apart they are.

Quantum entanglement allows qubits [quantum bits] that are separated by incredible distances to interact with each other immediately, in a communication that is not limited to the speed of light. No matter how great the distance between the correlated particles, they will remain entangled as long as they are isolated (Whatis. com, 2006).

Einstein called quantum entanglement a ,spooky action at a distance", but it is a really existing phenomenon that has been demonstrated in experiments, although the mechanism behind it cannot be fully explained by any existing theory. One proposal suggests that all particles on earth were once compacted tightly together and, as a consequence, maintain a connectedness. This includes the particles that make up each one of us. Recent events certainly reinforce the one-ness of humanity and the crises we face together, and the need to meliorate current conflicts between each other, and between us and the planet. This kind of perspective could lead to a new understanding our place in the universe, informing the way we conduct our behaviour.

In my research, I am also interested in 'entropy' and the application of Social Entropy Theory (SET) and the Second Law of Thermodynamics to networks, societies and civilizations. Social entropy measures the natural decay within a social system. It can comprise the disintegration of social structures and social relations. Legal institutions, as well as political and educational/scientific instutions expend much energy maintaining structures to decrease systemic entropy to try and maintain the system. But the Second Law of Thermodynamics states that entropy production is irreversible and tends to increase over time in any naturally occuring process. 'Anomie' is the maximum state of social entropy, which can lead to the general breakdown of social networks, the fragmentation of social identities and the regulatory function of social values in societies over time. Cooperation is replaced with conflict and chaos.

This kind of analysis of social phenomenon through the use of theory from the natural and physical sciences is gaining momentum. The world's problems are too complex, and interdependent to be defined within traditional disciplines. The challenge and responsibility of science today is to bring together people with different backgrounds and experience since no one has all the information required to deal with the gravity of issues we are facing.
The kinds of networks of which we are part of today appear to have deeply innovative qualities of density, temporality, spontaneity, and de-territorialization, crossing time as well as space. Recently, the Japanese government has decided to phase out the social sciences and humantities, claiming that they are no longer relevant to today's world and today's problems (Sawa, 2015). This action may be a bit extreme, but it does emphasize the challenge for the social sciences and humanities to become more relevant when addressing global issues. If we are condemned to live in extraordinary times, where all known 'truths' are being disputed, and where the certainties that have operated until now have evaporated, where does this leave the social sciences?

New management of the social sciences, connecting them with the natural sciences, is more important now than ever, and can become more relevant at times like these. In a complex world, the social sciences can act as the conscience and critique of societies and institutions. As social scientists, we engage in critical analysis that moves beyond the accumulation of data, to reflect, inform, and provide future alternatives and ways out of crisis. In contrast to journalists, politicians, and pundits, who are satisfied with soundbites, responsible social scientists accept the complexity of the age and refuse, for example, to see contemporary conflicts in the framework of a 'clash of civilizations', which inspired disastrous foreign policies for which both global peripheries and traditional centers are now paying a high price in terms of migration and terrorism. Relevant social sciences must challenge simplistic and black-andwhite thinking that reduces the hopes of hundreds of millions of people into simple contrasts between good and evil. Critical social scientists insist on the complexity of the world, and that there is nothing inevitable about neo-liberal capitalism, and that the withdrawal of the state from society and from its responsibilities is not a necessity, but a political choice. The perceived breakdown of basic civility, the return of nationalism and extremism in Europe, has more complex causes than the challenges of new migrations and immigrants. This may be out of step with the requirements of one type of contemporary reality, for example, reflected in the media, that performs an unrelenting 'social acceleration' where there is no time for detail, subtlety, balance and complex thinking, but it is crucial.

Another example can be taken from the management or rather mis-management of the financial crisis. When it came, and in its aftermath, it became clear that existing economic and financial models were seriously limited, oversimplistic and overconfident and actually helped to create the crisis in the first place. This is reflected in a combination of opinions not only from people who are skeptical of the neo-liberal, unregulated, post-Bretton 
Woods global capitalist system, but from people who actually worked at the heart of finance. All expressed concern that we do not understand the complexity or interdependence of the economic systems that drive our modern societies. We are, in fact, surrounded by systems made up of many interconnected and interacting parts like swarms of birds or fish, ecosystems, even brains, and this includes financial markets. Complexity theory tells us that what looks like complex behavior from the outside is actually the result of a few simple rules of interaction. So in order to begin to understand a system you need to look at the interactions.

Complex systems have a unique characteristic that is called 'emergence' which means that a system as a whole cannot be understood or predicted by examining the components of the system, because the system as a whole starts to reveal a particular behavior. Therefore, the whole is literally more than the sum of individual parts. Networks also represent complex systems and the nodes in a network are its components and the links are the interactions.

Applying this analysis to economic networks (but also to social and political networks) is new and reveals a surprising gap in the literature and analysis. In a definitive study Vitali, Glattfelder, Battiston (2011) present, for example, the extent of trans-national company (TNC) control of global wealth and finances. The TNC network they analyzed was structured with a periphery and a center. The center contained abour $75 \%$ of all players, and in the center there was a tiny but dominant core of highly interconnected companies. Although they only make up $36 \%$ of total TNCs, they control $95 \%$ of the total operating revenue of all TNCs.

After computing network control with 600,000 nodes of interconnections, they found that the top 737 shareholders (making up $0.123 \%$ ) have the potential to collectively control $80 \%$ of all TNC value. What are the implications of this high connection in the core of global finance? First of all, the high degree of control is extreme; and second, the high degree of interconnectivity of the top players in the core poses a significant systemic risk to the global economy, because any disruption in the core will quickly spread through the entire system. The study concludes that the network is probably the result of self-organization which is an emergent property and that the network depends on the rules of interaction in the system.

The realization that crisis is the new normal state of affairs requires radical and innovative rethinking, and not just palliatives. For example, we need to see the market as an aspect of human existence that cannot be divorced from the rest of life, yet the possibility that we should stop and rethink the market simply does not arise. Karl Polányi (2001) in The Great Transfor- mation, presented a set of interrelated and intertwined phenomena. With extraordinary prescience, he warned that crisis would come. He rejected the idea that the market is 'self-regulating' and can correct itself. There is no 'invisible hand' such as the market fundamentalists maintain, so there is nothing inevitable or 'natural' about the way markets work: they are always shaped by political decisions and powerful private interests. These observations and propositions were for the most part rather neglected during the past decades and by the explicit or tacit consensus of both social scientists and political analysts. In most cases analysts deal with each crisis as separate, isolated phenomena. This negligence and restricted perception (based upon the paradigm of the sovereign nation state and doctrine of independent academic disciplines) is greatly responsible for the present global turmoil which is at its heart a civilizational crisis. One of the major negative results is the lack of responsibility-taking for global or transnational disasters by the dominant players and stakeholders - from national and regional political leaders and institutions via institutions of knowledge creation and distribution including eminent social scientists.

This institutionalised irresponsibility and indifference surrounded by a tacit concensus about divided-ness as an unchangeable given is to a significant degree reponsible for undermining and emptying out democracies as well as for endangering the future of human existence on the planet. The recent return of the nation state and accompanying nationalistic cliches and prejudices within Europe and all around its borders resulted in the rise of rightwing and religious extremism, populism and an increasing rejection of multiculturalism. Xenophobia, racism and anti-semitism has been growing not only in the peripheries but also in the core countries of established democracies of affluent societies. This will only increase with the influx of refugees and migrants and the threat of new terrorist attacks, like in Paris, unless the inter-, cross-, multi-disciplinary 'wisdom of the crowd' can be leveraged to envision better possible futures.

The critical approach that is needed also leads to questions about the university itself, and about the research industry in which we are all embedded. The economic crisis became a pretext for profound transformations in how knowledge is produced and what kind of knowledge matters that we need to be aware of. We live in a complex, inter-dependent world where, on the one hand, governments say they need to downsize, open markets, and foster personal responsibility, while, at the same time they bail out banks and regulate our lives in increasingly invasive forms of controls over employment, personal conduct and appearance, and through surveillance. This also determines the nature 
of the research that is conducted. A creative, innovative and responsible approach to the social sciences and research entails a much greater engagement and deeper involvement in being a producer of ideas, a critic of society, and a member of intellectual networks where new ideas and new visions emerge for possible futures.

The social sciences needs to embrace uncertainty because " ... uncertainty is wondrous, and [if] certainty were to be real, would be moral death. If we were certain of the future, there would be no moral compulsion to do anything ... If everything is uncertain, then the future is open to creativity, not merely human creativity, but the creativity of all nature" (Wallerstein, 1999, p. 4.).

\section{References}

Arbesman, Samuel (2012): The Half Life of Facts: Why Everything We Know has an Expiration Date. New York: Penguin

Besnier, Niko (2010): "World Crisis and the Social Sciences". Lecture Delivered on the Occasion of the Opening of the Graduate School Academic Year. 3 September

Barret, William (1979): Illusion of Technique: A Search for Meaning in a Technological Civilization. New York: Anchor Books

Bohm, David (1980): Wholeness and the Implicate Order. New York and London: Routledge

Brynjolfsson, E. - MacAfee, A. (2014): The Second Machine Age: Work, Progress and Prosperity in a Time of Brilliant Technologies. NY: Norton

Bunge, Mario (2012): "Parallel Universes? Digital Physics?" Evaluating Philosophies, Boston Studies in the Philosophy and History of Science, 295, p. 151-157.

Cohen, E. - Lloyd, S. (2014): "Disciplinary Evolution and the Rise of the Transdiscipline". Informing Science: the International Journal of an Emerging Transdiscipline, 17, p. 189-215. http://www.inform. nu/Articles/Vol17/ISJv17p189-215Cohen0702.pdf

Csermely, Péter (2015): "Fast and Slow Thinking - of Networks." Cornell University Library. http://networkdecisions.linkgroup.hu/docs/fast-and-slow-arxiv2.pdf

Dirks, A. L. (1996): "Organization of Knowledge: The Emergence of Academic Specialty in America". http://webhost.bridgew.edu/adirks/ald/papers/orgknow.htm.

Einstein, Albert - Infeld, Leopold (1938): The Evolution of Physics: The Growth of Ideas From Early Concepts to Relativity and Quanta. Cambridge: Cambridge University Press

Eiseley, Loren (1964): "The Illusion of the Two Cultures." The American Scholar, Vol. 33, No. 3 (Summer), p. 387-399.
Frey, C. B. - Osborne, M. A. (2013): "The Future of Employment: How Susceptible Are Jobs to Computerisation?" http://www.oxfordmartin.ox.ac.uk/ downloads/academic.

Hellman, Hal (1998): Great Feuds in Science: Ten of the Liveliest Disputes Ever. New York: John Wiley $\&$ Sons, Inc.

Hellman, Hal (2004): Great Feuds in Technology: Ten of the Liveliest Disputes Ever. Hoboken, NJ: John Wiley \& Sons, Inc.

Hellman, Hal (2006): Great Feuds in Mathematics: Ten of the Liveliest Disputes Ever. Hoboken, NJ: John Wiley \& Sons, Inc.

Jackson, T. (2009): Prosperity Without Growth: Economics for a Finite Planet. London: Earthscan.

Jacobs, Alan (2014): "The Two Cultures, Then and Now." Books and Culture: A Christian Review (March/April). http://www.booksandculture.com/articles/2014/marapr/two-cultures-then-and-now.html.

Judge, Anthony (2012): "Knowledge Processes Neglected by Science: Insights from the Crisis of Science and Belief." (4 November). https://www.laetusinpraesens.org/musings/muversex.php.

Kingsley, D. (2014): The Phoenix Generation. London: Watkins Publishing

Kuhn, Thomas (1962): The Structure of Scientific Revolutions. Chicago: University of Chicago Press.

Ledford, Heidi (2015): "How to Solve the World's Biggest Problems," Nature 525 (September): 308-311. http://www.nature.com/news/how-to-solve-theworld-s-biggest-problems-1.18367.

Levy, Joel (2010): Scientific Feuds: from Galileo to the Human Genome Project. Chatswood, Australia: New Holland Publishers

Miszlivetz, Ferenc (ed.) (2014): Creative Cities and Sustainability. Szombathely: Savaria University Press

Oinas-Kukkonen, Harri (2008): "Network Analysis and Crowds of People as Sources of New Organisational Knowledge. in: A. Koohang et al. (eds.) (2008): Knowledge Management: Theoretical Foundation. Santa Rosa, CA: Informing Science Press, p. 173-189.

Pinker, Steven (2013): "Science is not Your Enemy: An Impassioned Plea to Neglected Novelists, Embattled Professors, and Tenure-less Historians." The New Republic (7 August). https://newrepublic.com/article/114127/science-not-enemy-humanities.

Planck, Max (1949): Scientific Autobiography. New York: Philosophical Library

Polányi, Karl (2001): The Great Transformation. 2nd ed. Boston: Beacon Press

Powel, Cory S. (2015): "Relativity versus Quantum Mechanics: The Battle for the Universe." The Guardian (4 November). http://www.theguardian. 
com/news/2015/nov/04/relativity-quantum-mechanics-universe-physicists.

Prigogine, Ilya (1996): The End of Certainty. New York: Free Press

Sawa, Takamitsu (2015): "Humanities under Attack." The Japan Times (23 August). http://www. japantimes.co.jp/opinion/2015/08/23/commentary/ japan-commentary/humanities-attack/\#.VkyDXvkveUk

Sheldrake, Rupert (2012): Science Set Free: Ten Paths to New Discovery. New York: Random House.

Snow, C. P. (1998): The Two Cultures. Cambridge: Cambridge University Press

Snow, C. P. (1959): The Two Cultures and Scientific Revolution. Cambridge: Cambridge University Press
Stoppard, Tom (1993): Arcadia. London: Samuel French Surokiecki, James (2004): The Wisdom of Crowds. New York: Anchor Books

Vitali, Stefania - Glattfelder, James B. - Battiston, Stefano (2011): "The Network of Global Corporate Control". http://arxiv.org/pdf/1107.5728.pdf

Wallerstein, Immanuel (1999): The End of the World as We Know it. Social Science for the 21st Century. Minneapolis: University of Minnesota Press

Wallerstein, Immanuel (2000): "Globalization or the Age of Transition? - A Long Term View of the Trajectory of the World System." International Sociology, Vol. 15, No. 2, p. 251-267.

Whatsit.com (2006): "Entanglement." http://whatis. techtarget.com/definition/entanglement. 